\title{
Multiple Routes of Entry for Escherichia coli Causing Colibacillosis in Commercial Layer Chickens
}

\author{
Hiroichi OZAKI ${ }^{1,2)}$ and Toshiyuki MURASE ${ }^{1,2) *}$ \\ ${ }^{1)}$ Laboratory of Veterinary Microbiology and ${ }^{2)}$ Avian Zoonosis Research Center, Faculty of Agriculture, Tottori University, Tottori 680 \\ 8553, Japan
}

(Received 9 June 2009/Accepted 18 August 2009)

\begin{abstract}
Colibacillosis associated with salpingitis occurred in a layer chicken flock on a commercial egg-producing farm in Japan. An increase in mortality was observed when the birds were at 62 weeks of age and reached $0.89 \%$ at 68 weeks of age. Postmortem examinations revealed pericarditis, perihepatitis, airsacculitis, and reproductive tract lesions in 4 affected birds at 69 weeks of age. Analysis of pulse-field gel electrophoresis (PFGE) patterns and putative virulence genes of 22 E. coli isolates obtained from the affected birds demonstrated that isolates from liver, heart, and the surface of the reproductive tract of one bird were genetically unrelated with those recovered from the lumen of the oviduct. In the other birds, isolates from liver, heart, and reproductive tract lesions were closely related to each other. These findings suggest that salpingitis in the former bird may be caused by ascending infection of the oviduct from the cloaca and salpingitis in the remaining birds may occur as part of systemic infection.

KEY WORDS: colibacillosis, layer chicken, salpingitis.
\end{abstract}

J. Vet. Med. Sci. 71(12): 1685-1689, 2009

Colibacillosis in poultry can be either localized or a systemic infection with Escherichia coli [2] and is characterized by a diverse array of lesions, although airsacculitis, perihepatitis, and pericarditis predominate [8]. The natural route of infection in colibacillosis is controversial but the oral and respiratory routes are considered to be significant [8]. E. coli strains, such as those that spread into various internal organs and cause colibacillosis characterized by systemic fatal disease are designated as avian pathogenic $E$. coli (APEC) [15]. Several putative virulence genes found in APEC have been suggested to play role in pathogenesis of colibacillosis. APEC is responsible for significant morbidity and mortality in the poultry industry worldwide [7, 11]. Although economic losses due to colibacillosis in broilers have been traditionally described [24], the cases in laying hens have only recently been recognized $[6,9,10,13,21$, 28]. Salpingitis, which is associated with colibacillosis, can be caused by both ascending infection of the oviduct from the cloaca and spread to the oviduct from airsacculitis as part of a systemic infection [2]. We have recently encountered cases of colibacillosis associated with salpingitis in layer chickens. To clarify routes of entry of E. coli in these birds, the present study compared isolates obtained from the reproductive tract, liver, air sac, and heart with respect to serotyping, pulse-field gel electrophoresis (PFGE)-based molecular typing, and the presence of the putative virulence genes.

A flock of White Leghorn hens comprising approximately 27,000 birds was reared in an environmentally controlled windowless house. In January 2009, a total of 73 birds $(0.28 \%)$ died at 62 weeks of age. The mortality rate

\footnotetext{
* Correspondence to: Murase, T., Laboratory of Veterinary Microbiology, Faculty of Agriculture, Tottori University, Tottori 680-8553, Japan.

e-mail: murase@muses.tottori-u.ac.jp
}

was approximately 1.5 -fold higher than that observed during the previous 2 to 3 weeks. The mortality rate gradually increased thereafter such that the number of dead birds reached 230 birds $(0.89 \%)$ at 68 weeks of age. Four birds at 69 weeks of age were submitted for postmortem examination. The postmortem state of these individuals was such that they were not considered to be appropriate for histological examination. Swabs collected from lesions of liver, heart, and air sac, mucosal lesions of the oviduct, uterine tube and vagina, and serosal surface of the uterine tube were individually subjected to bacteriological examination by streaking onto desoxycholate hydrogen sulfate (DHL) agar (Nissui Pharmaceutical Co., Ltd., Tokyo, Japan). Because the DHL plates yielded redish colonies in pure culture, 2 colonies were picked from each of the plates and the biochemical characteristics were determined using API20E (bioMerieux, Marcy-l'Etoile, France), and identified as $E$. coli. Serotyping of $E$. coli strains were performed by slide agglutination using commercially available $\mathrm{O}$-anti-sera (Denka Seiken Co., Ltd., Tokyo, Japan). PFGE patterns of $X b a \mathrm{I}$-digested chromosomal DNAs of all the isolates were analyzed as described elsewhere [19]. Eight putative virulence determinants, P-fimbriae ( $p a p C)$, aerobactin (iucD), iron-repressible protein (irp2), temperature-sensitive hemagglutinin $(t s h)$, vacuolating autotranspoter toxin (vat), enteroaggregative toxin (astA), increased serum survival protein (iss), and colicin V plasmid operon genes ( $c v a / c v i)$ were detected by a PCR assay with previously published primer pairs [9].

Postmortem examination in bird 1 revealed a shelled egg covered with fibrinous exudates in the vagina in which the mucosa appeared to be distended and inflammatory (Fig. 1A). Multiple masses of caseous exudates were demonstrated in the upper oviduct (Fig. 1B). The ovary was found to be degenerative, edematous, and yellowish in color. Peri- 


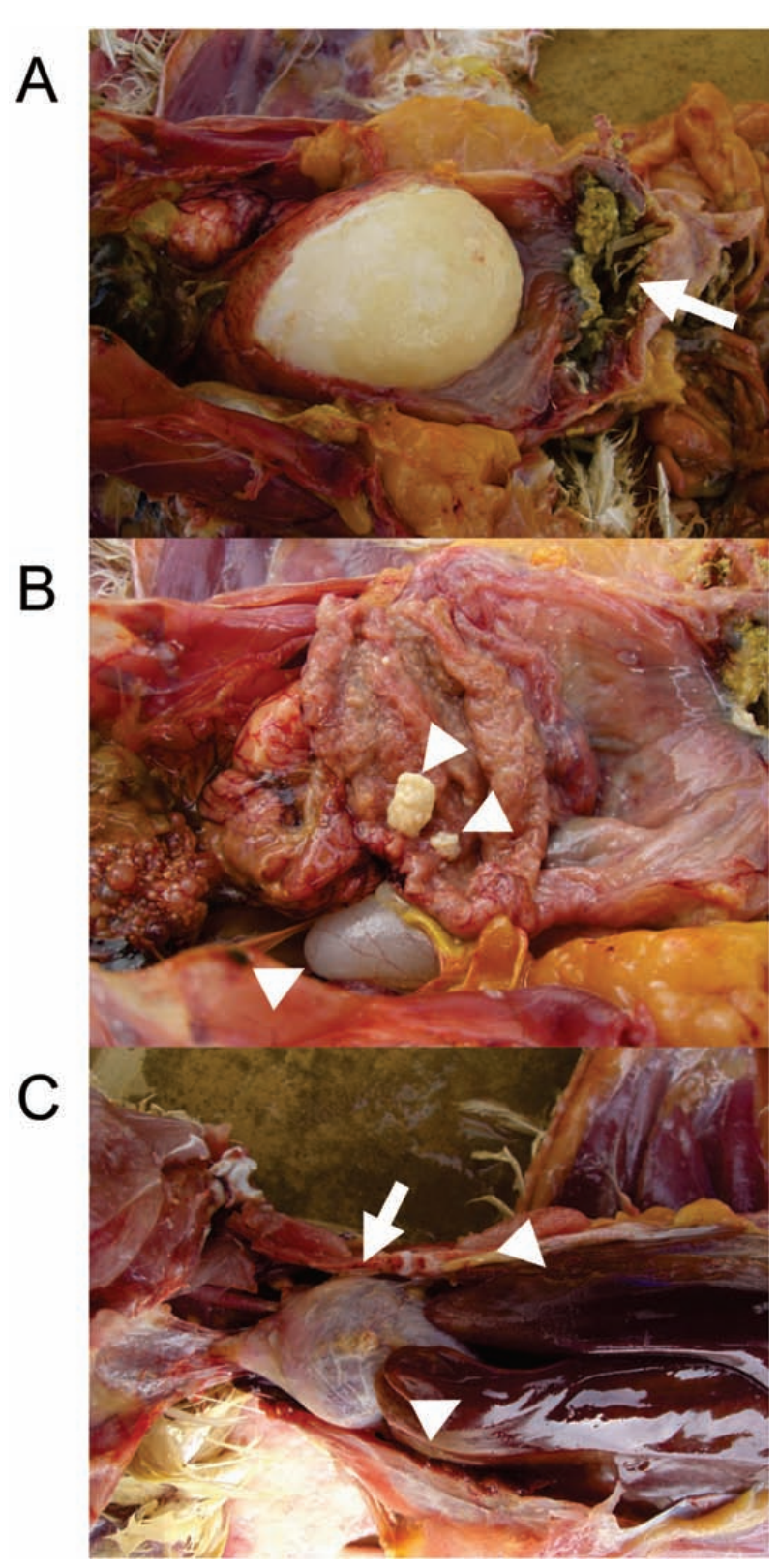

Fig. 1. Lesions in affected birds. (A) Shelled egg covered with fibrinous exudates in the vagina. Arrow indicates the cloaca. (B) Masses of caseous exudates in the oviduct and cystic right oviduct (arrowhead). (C) Pericarditis (arrow) and liver with slightly disposed fibrinous exudates (arrowhead).

hepatitis and airsacculitis were also observed in this bird. In bird 2, pericarditis and liver fibrinous exudates (Fig. 1C) were found, as was edema in the mucosa of the vagina containing a soft-shelled egg. The mucosa of the ampulla was slightly thickened and the ovary appeared to be grossly normal. Pericarditis was demonstrated in bird 3 but lesions in the reproductive tract were not found. In bird 4, the mucosa of the oviduct was thickened and edematous and multiple masses of caseous exudates were found in the oviduct lumen. Heart and liver in this bird were grossly normal.

A total of $22 \mathrm{E}$. coli isolates were obtained from the 4 affected birds above (Table 1). Serotypes found in the isolates included O25 (9 isolates), O125 (5), and O153 (1). Seven isolates from bird 1 were untypeable. PFGE patterns of the 22 isolates were classified by more than 7-band differences between each of 2 isolates and were arbitrarily designed as pattern A to $G$ (Fig. 2). Isolates belonging to the pattern $\mathrm{G}$ were further distinguished by one- to three-band differences and designated as G1 through G3. E. coli isolates obtained from the reproductive tract of bird 1 were classified into multiple PFGE patterns. Interestingly, PFGE patterns of isolates recovered from liver and air sac lesions and the serosal surface of the uterine tube were indistinguishable each other (pattern A) and distinct from those of the isolates obtained from the lumen of the reproductive tract (patterns $\mathrm{C}$ to $\mathrm{F}$ ). PFGE patterns observed in isolates from birds 2 through 4 belonged to pattern $\mathrm{G}$. Of the 22 isolates, 12 isolates with PFGE patterns C, D, E, F, and G harbored the putative virulence genes, iss, irp2, iucD, vat, or $c v a / c v i$. Isolates with the distinct PFGE patterns carried different combinations of these genes. One of 2 isolates with pattern $\mathrm{C}$ did not carry the cva/cvi gene (Table 1). Because the $c v a / c v i$ gene is mainly harbored on the ColV plasmid $[25,27]$, this isolate is unlikely to have the plasmid carrying this gene.

$E$. coli was considered as the causative agent of septicemia and salpingitis in birds in this commercial layer farm because this organism was isolated from typical lesions associated with colibacillosis. In this study, serotypes (O25, $\mathrm{O} 125$, and $\mathrm{O} 153$ ) of $E$. coli isolates obtained from the affected birds were infrequently reported in isolates associated with colibacillosis in chickens so far [16]. Although $\mathrm{O} 1, \mathrm{O} 2$, and $\mathrm{O} 78$ represent major $E$. coli serogroups that were associated with colibacillosis $[4,5,10,26]$, other serotypes have also caused this disease $[18,16]$, suggesting that serotypes of $E$. coli are not critical factors for the pathogenesis of colibacillosis in chicken. Any putative virulence genes tested were not detected in the isolates with PFGE pattern $\mathrm{A}$ and $\mathrm{B}$ although these isolates were obtained from typical colibacillosis lesions. Thus, other factors $[1,3,12$, $14,17,20]$ that were not examined in the present study may be associated with the pathogenesis.

Salpingitis in the affected birds in the present study possibly occurred through multiple routes of infection with $E$. coli. In bird 1, systemic infection may be caused by a strain with the PFGE pattern A that were obtained from liver, heart, and air sac lesions. Moreover, isolates obtained from the surface of the serosa of the oviduct showed the pattern A. Common PFGE patterns to the pattern A were, however, not recognized among 6 isolates (patterns $\mathrm{C}, \mathrm{D}$, and F) obtained from the reproductive tract lesions in this bird, indicating that E. coli strains with these PFGE patterns may ascend the oviduct from the cloaca. PFGE patterns of isolates obtained from heart and liver and reproductive tract lesions in bird 2 were indistinguishable from one another. Furthermore, PFGE patterns of isolates from the heart lesion 
Table 1. Characteristics of E. coli strains obtained from the affected birds

\begin{tabular}{|c|c|c|c|c|c|c|c|c|c|}
\hline \multirow[b]{2}{*}{ Isolate no. ${ }^{\text {a) }}$} & \multirow[b]{2}{*}{ Bird no. } & \multirow[b]{2}{*}{ Origin } & \multirow[b]{2}{*}{ Serotype ${ }^{c}$} & \multirow[b]{2}{*}{ PFGE pattern } & \multicolumn{5}{|c|}{ Presence of virulence-associated genes ${ }^{\mathrm{d})}$} \\
\hline & & & & & iss & $\operatorname{irp} 2$ & $i u c D$ & vat & $c v a / c v i$ \\
\hline D437 & 1 & Liver & 0125 & A & - & - & - & - & - \\
\hline D438 & 1 & Liver & UT & B & - & - & - & - & - \\
\hline D439 & 1 & Air sac & $\mathrm{O} 125$ & A & - & - & - & - & - \\
\hline D440 & 1 & Air sac & $\mathrm{O} 125$ & A & - & - & - & - & - \\
\hline D441 & 1 & Serosa of uterine tube & O125 & A & - & - & - & - & - \\
\hline D442 & 1 & Serosa of uterine tube & O125 & A & - & - & - & - & - \\
\hline D443 & 1 & Vagina $^{\text {b) }}$ & UT & $\mathrm{C}$ & + & + & - & + & - \\
\hline D444 & 1 & Vagina $^{\text {b) }}$ & UT & $\mathrm{D}$ & + & + & + & - & - \\
\hline D445 & 1 & Uterus $^{\text {b) }}$ & UT & $\mathrm{E}$ & + & + & - & - & + \\
\hline D446 & 1 & Uterus $^{\mathrm{b})}$ & UT & $\mathrm{C}$ & + & + & - & + & + \\
\hline D447 & 1 & Infundibulum $^{\text {b) }}$ & O153 & $\mathrm{F}$ & + & - & - & - & - \\
\hline D448 & 1 & Infundibulum $^{\text {b) }}$ & UT & $\mathrm{F}$ & + & - & - & - & - \\
\hline D449 & 2 & Liver/Heart & $\mathrm{O} 25$ & G1 & + & + & - & - & + \\
\hline D450 & 2 & Liver/Heart & $\mathrm{O} 25$ & G1 & + & + & - & - & + \\
\hline $\mathrm{D} 451$ & 2 & Uterus $^{\text {b) }}$ & $\mathrm{O} 25$ & G1 & + & + & - & - & + \\
\hline D452 & 2 & Uterus $^{b)}$ & $\mathrm{O} 25$ & G1 & + & + & - & - & + \\
\hline D453 & 2 & Ampulla of oviduct ${ }^{\text {b) }}$ & $\mathrm{O} 25$ & G1 & + & + & - & - & + \\
\hline D454 & 2 & Ampulla of oviduct ${ }^{\text {b) }}$ & $\mathrm{O} 25$ & G1 & + & + & - & - & + \\
\hline D455 & 3 & Heart & UT & G1 & + & + & - & - & + \\
\hline D456 & 3 & Heart & $\mathrm{O} 25$ & G1 & + & + & - & - & + \\
\hline D457 & 4 & Oviduct $^{\mathrm{b})}$ & $\mathrm{O} 25$ & $\mathrm{G} 2$ & + & + & - & - & + \\
\hline D458 & 4 & Oviduct ${ }^{\text {b) }}$ & $\mathrm{O} 25$ & G3 & + & + & - & - & + \\
\hline
\end{tabular}

a) Each of 2 isolates with 2 consecutive numbers were obtained from each of the lesions.

b) Swabs were obtained from mucosal lesions.

c) UT, untypeable.

d) + and -, gene detected and undetected, respectively, by PCR.

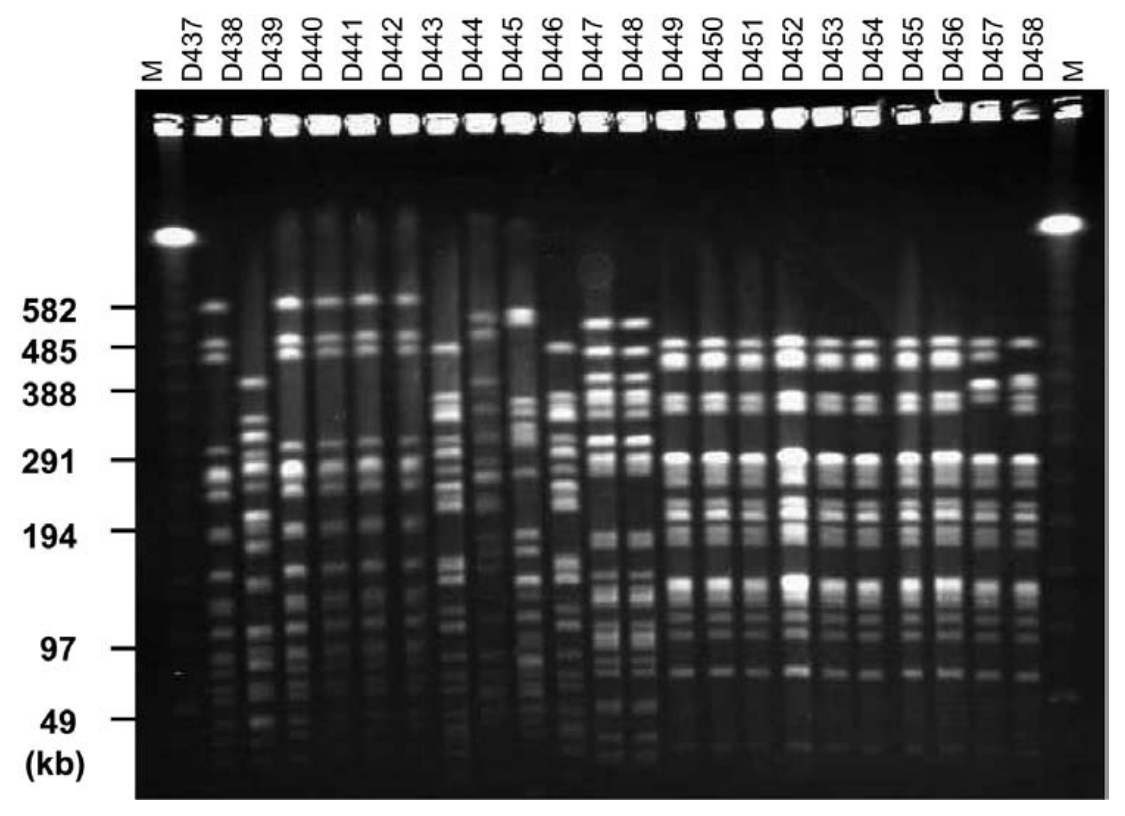

Fig. 2. PFGE patterns of $X b a \mathrm{I}$-digested chromosomal DNA of $E$. coli isolates obtained from affected chickens. The number on each lane is the isolate number from Table 1. Lane M, lambda DNA ladder.

in bird 3 were identical to those shown in isolates from bird 2 and isolates from the oviduct lesion in bird 4 were closely related to those from birds 2 and 3 according to the estab- lished criteria for subtyping of bacteria by PFGE [23], suggesting that the strain with this PFGE profile (pattern G) may be a common causative agent. Thus, the cases includ- 
ing birds 2 through 4 in the present study may be a part of an outbreak caused by infection with an E. coli strain exhibiting the PFGE pattern $G$ which resulted in $0.9 \%$ bird mortality in the house the previous week. Our previous study demonstrated that only a limited number of $E$. coli clones, confirmed by PFGE, were associated with systemic colibacillosis infection that occurred in laying hens in a commercial egg-producing farm [22]. Monroy et al. [18] demonstrated that characteristics of $E$. coli isolates obtained from broiler breeders with salpingitis were similar to those of strains of $E$. coli isolated from cases of chronic respiratory disease and colicepticemia in terms of the production of siderophores and aerobactin and pathogenicity for day-old chicks. These observations and our results suggest that spread to the oviduct is likely to occur as a part of systemic infection in birds 2 through 4 although the oviduct lesions were not found in a bird. Further study needs to investigate specific factor(s) responsible for $E$. coli colonization in the reproductive tracts.

ACKNOWLEDGMENT. The authors are grateful to Dr. Peter S. Holt (Egg Safety and Quality Research Unit, United States Department of Agriculture, U.S.A.) for reviewing the manuscript.

\section{REFERENCES}

1. Allan, B. J., van den Hurk, J. V. and Potter, A. A. 1993. Characterization of Escherichia coli isolated from cases of avian colibacillosis. Can. J. Vet. Res. 57: 146-151.

2. Barnes, H. J., Vaillancourt, J.-P. and Gross, W. B. 2003. Colibacillosis. pp. 631-652. In: Diseases of Poultry, 11th ed. (Saif, Y. M., Barnes, H. J., Glisson, J. R., Fadly, A. M., McDougald, L. R. and Swayne, D. E. eds.), Iowa State Press, Ames.

3. Blanco, J. E., Blanco, M., Mora, A. and Blanco, J. 1997. Production of toxins (enterotoxins, verotoxins, and necrotoxins) and colicins by Escherichia coli strains isolated from septicemic and healthy chickens: relationship with in vivo pathogenicity. J. Clin. Microbiol. 35: 2953-2957.

4. Cheville, N. F. and Arp, L. H. 1978. Comparative pathologic findings of Escherichia coli infection in birds. J. Am. Vet. Med. Assoc. 173: 584-587.

5. Cloud, S. S., Rosenberger, J. K., Fries, P. A., Wilson, R. A. and Odor, E. M. 1985. In vitro and in vivo characterization of avian Escherichia coli. I. Serotypes, metabolic activity, and antibiotic sensitivity. Avian Dis. 29: 1084-1093.

6. Dhillon, A. S. and Jack, O. K. 1996. Two outbreaks of colibacillosis in commercial caged layers. Avian Dis. 40: 742-746.

7. Dho-Moulin, M. and Fairbrother, J. M. 1999. Avian pathogenic Escherichia coli (APEC). Vet. Res. 30: 299-316.

8. Dziva, F. and Stevens, M. P. 2008. Colibacillosis in poultry: unravelling the molecular basis of virulence of avian pathogenic Escherichia coli in their natural hosts. Avian Pathol. 37: 355-366.

9. Ewers, C., Janssen, T., Kiessling, S., Philipp, H. C. and Wieler, L. H. 2004. Molecular epidemiology of avian pathogenic Escherichia coli (APEC) isolated from colisepticemia in poultry. Vet. Microbiol. 104: 91-101.

10. Ewers, C., Janssen, T., Kiessling, S., Philipp, H. C. and Wieler, L. H. 2005. Rapid detection of virulence-associated genes in avian pathogenic Escherichia coli by multiplex polymerase chain reaction. Avian Dis. 49: 269-273.

11. Ewers, C., Janssen, T. and Wieler, L. H. 2003. Avian pathogenic Escherichia coli (APEC). Berl Münch. Tierärztl. Wochenschr. 116: 381-395.

12. Gomis, S. M., Riddell, C., Potter, A. A. and Allan, B. J. 2001. Phenotypic and genotypic characterization of virulence factors of Escherichia coli isolated from broiler chickens with simultaneous occurrence of cellulitis and other colibacillosis lesions. Can. J. Vet. Res. 65: 1-6.

13. Janben, T., Schwarz, C., Preikschat, P., Voss, M., Philipp, H. C. and Wieler, L. H. 2001. Virulence-associated genes in avian pathogenic Escherichia coli (APEC) isolated from internal organs of poultry having died from colibacillosis. Int. J. Med. Microbiol. 291: 371-378.

14. Johnson, L. C., Bilgili, S. F., Hoerr, F. J., McMurtrey, B. L., and Norton, R. A. 2001. The influence of Escherichia coli strains from different sources and the age of broiler chickens on the development of cellulitis. Avian Pathol. 30: 475-478.

15. La Ragione, R. M. and Woodward, M. J. 2002. Virulence factors of Escherichia coli serotypes associated with avian colisepticaemia. Res. Vet. Sci. 73: 27-35.

16. McPeake, S. J., Smyth, J. A. and Ball, H. J. 2005. Characterisation of avian pathogenic Escherichia coli (APEC) associated with colisepticaemia compared to faecal isolates from healthy birds. Vet. Microbiol. 110: 245-253.

17. Mellata, M., Bakour, R., Jacquemin, E. and Mainil, J. G. 2001. Genotypic and phenotypic characterization of potential virulence of intestinal avian Escherichia coli strains isolated in Algeria. Avian Dis. 45: 670-679.

18. Monroy, M. A., Knobl, T., Bottino, J. A., Ferreira, C. S. and Ferreira, A. J. 2005. Virulence characteristics of Escherichia coli isolates obtained from broiler breeders with salpingitis. Comp. Immunol. Microbiol. Infect. Dis. 28: 1-15.

19. Murase, T., Nagato, M., Shirota, K., Katoh, H. and Otsuki, K. 2004. Pulsed-field gel electrophoresis-based subtyping of DNA degradation-sensitive Salmonella enterica subsp. enterica serovar Livingstone and serovar Cerro isolates obtained from a chicken layer farm. Vet. Microbiol. 99: 139-143.

20. Ngeleka, M., Kwaga, J. K., White, D. G., Whittam, T. S., Riddell, C., Goodhope, R., Potter, A. A. and Allan, B. 1996. Escherichia coli cellulitis in broiler chickens: clonal relationships among strains and analysis of virulence-associated factors of isolates from diseased birds. Infect. Immun. 64: 31183126.

21. Rodriguez-Siek, K. E., Giddings, C. W., Doetkott, C., Johnson, T. J., Fakhr, M. K. and Nolan, L. K. 2005. Comparison of Escherichia coli isolates implicated in human urinary tract infection and avian colibacillosis. Microbiology 151: 20972110.

22. Someya, A., Otsuki, K. and Murase, T. 2007. Characterization of Escherichia coli strains obtained from layer chickens affected with colibacillosis in a commercial egg-producing farm. J. Vet. Med. Sci. 69: 1009-1014.

23. Tenover, F. C., Arbeit, R. D., Goering, R. V., Mickelsen, P. A., Murray, B. E., Persing, D. H. and Swaminathan, B. 1995. Interpreting chromosomal DNA restriction patterns produced by pulsed-field gel electrophoresis: criteria for bacterial strain typing. J. Clin. Microbiol. 33: 2233-2239.

24. Vandekerchove, D., Vandemaele, F., Adriaensen, C., Zaleska, M., Hernalsteens, J. P., De, B. L., Butaye, P., Van, I. F., Wattiau, P., Laevens, H., Mast, J., Goddeeris, B. and Pasmans, F. 2005. Virulence-associated traits in avian Escherichia coli: 
comparison between isolates from colibacillosis-affected and clinically healthy layer flocks. Vet. Microbiol. 108: 75-87.

25. Vidotto, M. C., Muller, E. E., de Freitas, J. C., Alfieri, A. A., Guimaraes, I. G. and Santos, D. S. 1990. Virulence factors of avian Escherichia coli. Avian Dis. 34: 531-538.

26. Whittam, T. S. and Wilson, R. A. 1988. Genetic relationships among pathogenic strains of avian Escherichia coli. Infect. Immun. 56: 2458-2466.

27. Wooley, R. E., Brown, J., Gibbs, P. S., Nolan, L. K. and
Turner, K. R. 1994. Effect of normal intestinal flora of chickens on colonization by virulent colicin V-producing, avirulent, and mutant colicin V-producing avian Escherichia coli. Avian Dis. 38: 141-145.

28. Zanella, A., Alborali, G. L., Bardotti, M., Candotti, P., Guadagnini, P. F., Martino, P. A. and Stonfer, M. 2000. Severe Escherichia coli $\mathrm{O} 111$ septicaemia and polyserositis in hens at the start of lay. Avian Pathol. 29: 311-317. 